\title{
TU/e EnNHONEN

\section{A gap-theoretical path model of residential satisfaction and intention to move house applied to renovated historical blocks in two Chinese cities}

\section{Citation for published version (APA):}

Jiang, W., Feng, T., Timmermans, H. J. P., \& Li, H. (2017). A gap-theoretical path model of residential satisfaction and intention to move house applied to renovated historical blocks in two Chinese cities. Cities, 71 , 19-29. https://doi.org/10.1016/j.cities.2017.06.021

\section{Document license:}

TAVERNE

DOI:

10.1016/j.cities.2017.06.021

Document status and date:

Published: 01/11/2017

\section{Document Version:}

Publisher's PDF, also known as Version of Record (includes final page, issue and volume numbers)

\section{Please check the document version of this publication:}

- A submitted manuscript is the version of the article upon submission and before peer-review. There can be important differences between the submitted version and the official published version of record. People interested in the research are advised to contact the author for the final version of the publication, or visit the $\mathrm{DOI}$ to the publisher's website.

- The final author version and the galley proof are versions of the publication after peer review.

- The final published version features the final layout of the paper including the volume, issue and page numbers.

Link to publication

\footnotetext{
General rights

- You may freely distribute the URL identifying the publication in the public portal. follow below link for the End User Agreement:

www.tue.nl/taverne

\section{Take down policy}

If you believe that this document breaches copyright please contact us at:

openaccess@tue.nl

providing details and we will investigate your claim.
}

Copyright and moral rights for the publications made accessible in the public portal are retained by the authors and/or other copyright owners and it is a condition of accessing publications that users recognise and abide by the legal requirements associated with these rights.

- Users may download and print one copy of any publication from the public portal for the purpose of private study or research.

- You may not further distribute the material or use it for any profit-making activity or commercial gain

If the publication is distributed under the terms of Article 25fa of the Dutch Copyright Act, indicated by the "Taverne" license above, please 


\title{
A gap-theoretical path model of residential satisfaction and intention to move house applied to renovated historical blocks in two Chinese cities
}

\author{
Wen Jiang ${ }^{\mathrm{a}, *}$, Tao Feng ${ }^{\mathrm{a}}$, Harry Timmermans ${ }^{\mathrm{a}}$, Heping $\mathrm{Li}^{\mathrm{b}}$ \\ a Eindhoven University of Technology, The Netherlands \\ b Chongqing University, China
}

\section{A R T I C L E I N F O}

\section{Keywords:}

Intention to move

Residential satisfaction

Path analysis

\begin{abstract}
A B S T R A C T
Using data from eight historical blocks in two selected Chinese cities, this article presents the results of a path model, which captures both the direct and indirect relationships between social-demographics, residential satisfaction and intention to move. Using a gap theoretical framework, results of the path analysis suggest that the intention to move house is significantly and negatively affected by residential satisfaction. In turn, residential satisfaction is significantly influenced by the gap between aspired and actual housing and environmental attributes, proportional to aspiration level. Additionally, the intention to move house and the residential gap are influenced by a set of physical and social-demographical profiles. Residents who rent a house have a lower intention to move, while people living in historical blocks that are at the early renovation stage have a higher propensity to move. Among the various social demographical variables, age is found to be the most influential one, showing that older inhabitants have a lower intention to move house than younger inhabitants.
\end{abstract}

\section{Introduction}

First-time travellers arriving in China are often surprised about the western appearance of Chinese cities. The traditional historical blocks, which they remember from old photographs and movies, are difficult to find. The term historical block and district refer to those areas in Chinese cities, where historical or cultural buildings gather, or present the characteristics and style of a certain historical period. ${ }^{1}$ From the 1980s onwards, several rounds of regeneration projects in most first-tier Chinese cities (i.e. mega-cities displaying strong political and economic influence within China with a high yearly GDP growth over 7\%) have ruined a large percentage of these historical blocks. This regeneration coincided with the displacement of a large number of residents and a transformation of the residential environment (Yang \& Wu, 1999). To both protect and develop the few remaining historical blocks, renovation became popular. Although scholars preferred to emphasize that additional proper renovations were needed for these blocks due to their terrible physical conditions and financial issues (Ruan, 2004; Wang, 2008), social problems due to the changed living environment during and after renovation cannot be neglected (Yang \& Wu, 1999).

Over the past three decades, social problems caused by renovation of historical blocks in Chinese cities have become increasingly complicated. Forced relocation led by local government was identified as the cause of occurring social problems. However, after the implementation of the Real Right Law in 2007, continuing social problems and conflicts were not only caused by forced relocation that had become much less frequent. Rather, unsatisfied housing aspirations of residents and decaying social bonding within neighbourhoods became the new major drivers of social problems. Recently, due to decreasing residential satisfaction and/or increasing housing aspirations, even without forced relocation, residents continue to move out of historical blocks, accelerating the deterioration of the social fabric and perpetuating social problems. As all these social problems are associated with relocation, and local government and residents alike contribute to these problems, mainstream planning studies of renovated Chinese historical blocks that solely blamed local government (He \& Deng, 2014; Jin, 2005) at best only provide a partial understanding of residential moves from historical blocks in Chinese cities. Analysis of residential mobility from the inhabitants' perspective is needed to get a better and more balanced understanding of these residential processes. Rather than blaming administration as the only reason for residential mobility, we assume that a more complex process, in which government may trigger changes in housing supply and respond insufficiently or inappropriately to housing and neighbourhood deterioration, triggers residential mobility. As a result, residents become increasingly less satisfied with the increasing gap between their housing aspirations and the reality they

\footnotetext{
* Corresponding author at: Urban Planning Group, Eindhoven University of Technology, PO Box 513, Den Dolech 2, 5600 MB Eindhoven, The Netherlands.

E-mail address: w.jiang@tue.nl (W. Jiang)

${ }^{1}$ Ministry of Construction of the People's Republic of China, May 1985.
} 
experience on a daily basis, and therefore, at some stage, develop the intention to move house and actually move house once the opportunity arises and they can afford it.

There is abundant empirical evidence across the world that residential mobility is influenced by a myriad of different factors. Clark and Onaka (1983) in their study in the USA found that housing attributes, neighbourhood characteristics and accessibility were the main reasons causing residential mobility. Additional factors that were found to be correlated with the probability of moving house include tenure (Clark \& Huang, 2003; Ioannides, 1987), length of stay (Onaka \& Clark, 1983) and lifecycle (Feijten \& van Ham, 2007; Rabe \& Taylor, 2010). Residential satisfaction was also found to influence the intention to move (Kearns \& Parkes, 2003; Kwon \& Beamish, 2013; Oh, 2003).

However, a limitation of the majority of these studies is that they have examined bivariate relationships between housing attributes, satisfaction, intention to move and actual movement patterns. Ignoring relevant factors may bias the results and even lead to erroneous conclusions and interpretations. Attempts to combine more of these concepts into a single, integrated analysis are still scarce. It implies that we have relatively little empirical evidence about the direct and indirect relationships between housing attributes, residential satisfaction and intention to move based on data from the same sample.

The vast majority of housing studies pertains to residential moves in non-regulated or semi-regulated housing markets that prevail under political systems that fundamentally differ from the Chinese system in general and particularly from historical blocks. Meanwhile, different from residents in other non-historical urban areas, those living in historical blocks are facing distinct constraints. On the one hand, these residents face much worse housing conditions and fewer own their houses; on the other hand, their houses are located in the centre of cities with a high cultural value, in neighbourhoods with traditionally a better social bonding. Facing both these negative and positive living conditions, residents may consider these trade-offs in considering to move house or not. The question, therefore, is whether the concepts used in the prevalent western studies and their findings can be generalised to Chinese historical blocks. This is one of the research questions that will be addressed in the present study.

Generally, the approach adopted in studies of residential mobility is to break down the problem into constituent components and study each of these separately. Hence, assuming interval properties of the satisfaction scale, ordinary linear regression analysis has been commonly used to examine the degree of residential satisfaction as a function of housing and neighbourhood characteristics, accessibility and socio-demographics, lifestyle and life trajectory (e.g., Addo, 2016; Kährik, Leetmaa, \& Tammaru, 2012; Mohit \& Adel Mahfoud, 2015; Posthumus, Bolt, \& van Kempen, 2014; Temelová \& Dvořáková, 2012). Likewise, the decision to move house has been studied using discrete choice models. Residential choice probabilities have been investigated as a function of the same set of variables or as a function of residential satisfaction (e.g., Dane, Griglon, Rasouli, \& Timmermans, 2014). In this paper, rather than adopting this two-step, we formulate and estimate an integrated path model that allows the estimation of the direct and indirect effects between personal and household characteristics, housing and neighbourhood characteristics, residential satisfaction and the intention to move house.

Thus, this paper will systematically study how residential mobility is influenced by residential satisfaction, which is conceptualised as the gap between housing aspirations and reality, proportional to aspiration level. The aim of this paper is to analyse both the direct and indirect relationships between intention to move, residential satisfaction, residential gap and social demographics in selected Chinese historical blocks using a gap-theoretical framework. Path analysis is used to estimate the complex relationships using data collected in eight renovated historical blocks in two selected cities, Chongqing and Shanghai, in China. Findings of the study have implications for urban planners and local governments to improve the living environment in renovated historical blocks. These implications are not only confined to the selected blocks, but may be equally relevant for other cities and countries. The particularity of these historical blocks is articulated by comparing to the finding of previous studies on residential satisfaction and mobility in other urban areas. The gap-theoretical framework can contribute to the current residential theories and be used for future residential studies.

The structure of this paper is as follows. The next section will discuss some relevant literature on residential mobility. Our conceptual model, based on the gap-theoretical framework, will be presented in the subsequent section. The section on data collection will describe where and how the data was collected. The last section will present the results of the data analysis, which is followed by a discussion of the implications of our findings for urban planning and housing policy.

\section{Literature review}

Finding determinants of residential mobility has been a popular topic in housing research since many decades. A plethora of studies have found evidence that the probability of moving house is significantly and negatively related to residential satisfaction (e.g., Kearns \& Parkes, 2003; Kim, Woosnam, Marcouiller, \& Aleshinloye, 2015; Kwon \& Beamish, 2013; Oh, 2003). Authors such as Speare (1974), Landale and Guest (1985), Earhart and Weber (1996), Kwon and Beamish (2013) and Kearns and Parkes (2003) found that dissatisfaction increases the intention to move. In turn, Diaz-Serrano and Stoyanova (2010) asserted that the propensity to move is systematically but not perfectly related to actual moves. This non-perfect relationship may be explained by the fact that the wish to move may not always be realised due to a lack of resources and/or market conditions. The high transition costs and the effort involved may lead people to postpone or change their plans to move house. Another factor may be that demographic or economic factors may change an individual's or household's housing needs, implying that an existing intention to move house is not transformed into actual residential mobility.

Traditionally, the number of Chinese studies on housing satisfaction and residential mobility has been modest. Although an increasing number of Chinese studies tried to identify the determinants of residential mobility (e.g., He, 2015; Huang \& Deng, 2006; Huang, Dijst, van Weesep, \&Zou, 2014; Hui \& Yu, 2009; Li, 2003; Wu, 2006), few scholars have examined the relationship between residential satisfaction and residential mobility. For example, using data from inner-city Beijing, Fang (2006) confirmed results of western studies, indicating that low satisfaction leads to a high moving intention. Tao, Wong, and Hui (2014), examining migrant workers living in Shenzhen, found that mobility preferences influence residential satisfaction. To the best of our knowledge, research about historical blocks has not studied this relationship yet.

The vast majority of studies assumed that residential satisfaction is a function of three dimensions: (i) housing attributes; (ii) neighbourhood characteristics, and (iii) relative location vis-à-vis various facilities. Usually, neighbourhood characteristics include a set of morphological and functional characteristics, but social composition is sometimes also included. For instance, He and Yang (2011), Huang and Du (2015) and Ren and Folmer (2016) found that community facilities exert a strong influence on residential satisfaction. Social factors such as crime and ethnical composition have also been identified as influential factors (e.g., Parkes, Kearns, \& Atkinson, 2002 and Clark \& Coulter, 2015). Other factors, including tenure (e.g., Hu, 2013; Huang et al., 2015; Molin \& Timmermans, 2003), and age of inhabitants (e.g., Grigolon, Dane, Rasouli, \& Timmermans, 2014; Waziri, Yusof, \& Abd Rahim, 2014), have also been investigated as determinants of residential satisfaction. However, these research only assessed the direct effect of the influential factors on residential satisfaction. It means that such studies, implicitly or explicitly, have assumed that people with the same sociodemographic profile will derive the same satisfaction from particular 
housing attributes or characteristics of the neighbourhood. In reality, however, different people may have different levels of aspiration, which may lead to varying satisfaction, even for the same attribute values or levels. An increasing mismatch between aspirations and the daily experienced real situation may result in lower satisfaction. Thus, change of residents' satisfaction may not only be caused by attributes of the house and the environment, but may also reflect a change in their aspiration levels.

To accommodate theoretically the interdependency between satisfaction and aspiration, we use gap-theory as the theoretical foundation of this study. Galster (1987) introduced gap theory into housing studies and argued that residential satisfaction is a function of the gap between the perceived actual environment and the aspired environment. Although this concept has been adopted by several scholars to study residential satisfaction (e.g., Campbell, Converse, \& Rodgers, 1976; Tang, 2012), the operationalization of the concept has remained simple. Thus, we will further elaborate this concept and explore more into the relationship between aspiration and residential satisfaction at the individual level.

Another concept similar to gap that has often been adopted in residential studies is stress. Wolpert (1965) was among the first to argue that humans try to fulfil many needs to satisfy their aspirations. These needs are also projected onto housing attributes. If the actual attributes of a house fail to meet their aspirations, individuals will experience a certain degree of stress. Dynamically, the natural deterioration of housing quality and rising aspirations resulted from particular economic or demographic events may increase the degree of stress. Once it exceeds a certain threshold, according to this theory, people start searching for alternative housing, and will move house when they find a stress-reducing and affordable house.

Brown and Moore (1970) improved the stress concept by conceptualising stress as a mismatch between the needs of households and the characteristics of housing situation. Later, Huff and Clark (1978), Brummell (1979, 1981) and Phipps and Carter (1984) and Phipps (1989) added the concept of resistance to this theory by examining the joint influence of resistance and stress on residential mobility. The notion of resistance emphasizes the fact that change (residential moves) involves a lot of effort and costs and therefore people may postpone the searching process or even never act on their desire to search for another house.

Stress shows a lot of similarity with the notion of gap; both concepts concern the mismatch between the aspired and perceived or experienced actual situation. However, because readers may associate the concept of stress with the notion of a psychological disposition, we prefer to use the concept of residential gap. Again, to emphasize, this concept claims that residential satisfaction is not determined by the actual values of house and neighbourhood attributes per se, but rather by a function of the discrepancy between the aspired and actual or perceived attributes.

Residential satisfaction has also been analysed as an intervening variable to explain residential mobility. Speare (1974) first used satisfaction as a mediator between individual and residential variables and residential mobility, including the propensity to move and the real move. It is concluded that social-demographic characteristics influence both types of moves through satisfaction. This finding was later confirmed by Oh (2003) and Diaz-Serrano and Stoyanova (2010). By analysing the data from 12 countries, Diaz-Serrano and Stoyanova (2010) confirmed that, in the majority of the selected countries, the mediating effect of residential satisfaction on mobility propensity is very strong. Deane (1990) who expanded the Speare's model by adding adjustment, such as financial investment, as the mediation between satisfaction and intention to move, also found a strong impact on intention to move. Oppositely, Landale and Guest (1985) conducted a similar analysis, but found that residential satisfaction has little influence on mobility as a mediator variable of social-demographics, although it directly and strongly influences thoughts of moving house.
The mediating effect of residential satisfaction was also not supported in findings from Liao (2004). It should be noted that most of the research can be viewed as a replication of Speare's study in the sense that residential satisfaction was used as a mediator variable between socialdemographics, residential variables and residential mobility. Residents' aspirations were not taken into consideration.

Compared with the studies focusing on the direct relationships between residential attributes, residential satisfaction and residential mobility, the studies using residential satisfaction as an intervening variable are not confined to one specific quantitative relationship, but take into account logically more complicated direct and indirect relationships. While the direct relationships are usually estimated using ordinary linear regression or discrete choice models, path and structural equation models have been the dominant models to analyse the complex relationships.

Although Speare (1974) claimed that social-demographic variables, such as age, income and length of stay, should not directly influence moving intention but through some mediation, most research still tends to analyse the direct influence of those variables on residential mobility. Besides the above-mentioned tenure, length of stay and lifecycle, age and gender have been considered in most residential mobility studies. All studies indicate that residents are less likely to move with increasing age, while the effect of gender varies. Moreover, education has been shown to affect mobility significantly (e.g., Green, 2014; Kim et al., 2015; Wu, 2006). Specifically, Wu (2006) found that education shows a significant positive effect on both the intention to move and actual moves. Later, Green (2014) and Kim et al. (2015) confirmed such findings.

Regarding Chinese studies, residential mobility has attracted increasing interest from 2000 onwards (e.g. Fang, 2006; Huang, Du, \& Yu, 2015; Li \& Song, 2009; Li \& Wu, 2013; Tao et al., 2014). Most of these studies assess the direct relationship between social-demographic variables, residential satisfaction and mobility. Only Liao (2004) analysed the intervening effect of residential satisfaction, taking into consideration the indirect relationship between housing attributes, intention to move and having made moving plans. The findings of these studies are not always consistent with those of western studies (e.g., Fang, 2006; Li, 2003; Li, 2004; Wu, 2006). Specifically, Li (2003) and Wu (2006) found that tenure change does not necessarily drive the residential move like findings in the Western literatures. Li (2004) found that lifecycle events, such as marriage and childbirth, exert minimal influence on residential mobility, which is also different from western findings. Fang (2006) found that low residential satisfaction does not induce moving behaviour. The discrepancy in findings may be associated to the different social contexts and constraints faced by Chinese people.

When focusing on historical blocks, Chinese scholars have studied housing mainly from the macro-level perspective. Although much less forced relocation can be observed after 2007, local government is still blamed as the main cause of social problems and residential mobility (He \& Deng, 2014). Physical protection of historical blocks is another topic that has triggered the interest of Chinese scholars (Chen, Xu, \& Jing, 2009). Little research has been devoted to the residents' perspective. To the extent it consists, it tends to concentrate on public participation in renovation (e.g., Zheng \& Yang, 2005; Zhong \& Kou, 2015).

To summarise, accumulated evidence in housing studies, particularly concerned with developed economies, suggests that residential satisfaction is systematically but not perfectly related to the intention to move house and the ultimate housing mobility decision. The literature differs in the sense that some authors have assumed a direct relationship whereas others have assumed an indirect relationship in which residential satisfaction is used as an intervening variable. Relative to the abundant literature in developed countries, the literature on housing satisfaction and residential mobility in emerging economies, such as China, is modest at best. The literature focusing on residential 
preferences, satisfaction and mobility in historical blocks is really scarce. This lack of interest is in flagrant contrast with the importance and relevance of this topic in that various constraints influence the relationship between residential satisfaction and intention to move. Although the concepts of gap and stress have played a role in the literature, attempts to systematically measure the gap between aspirations and the actual housing situation and include them in the analysis have been limited. In this paper, by comprehensively studying the relations between social-demographic variables, residential gap, dimensions of satisfaction and intention to move, an integrated conceptual framework and model that measures both the direct and indirect relationships between those variables will be presented.

\section{Conceptual framework}

Housing is a basic need of individuals and households. Housing aspirations change in response to lifecycle, economic prosperity, housing supply and market conditions. At the same time, supply and resource constraints imply that people may not always be able to realise their aspirations. Consequently, there may be a mismatch between their housing aspirations and the reality they face on a daily basis. If this mismatch is substantial or grows through life-course events, and exceeds a certain threshold, people are likely to develop the intention to move, subject to the constraints they face. For instance, having a baby might lead to a larger gap between aspiration and reality, which may further cause the intention to move house.

Different people have different aspiration levels that lead to different degrees of satisfaction. Residential satisfaction is thus assumed influenced by a change of aspiration related to residential variables rather than directly influenced by the value of these variables. In line with classical gap theory, residential gap defined as the gap between residents' aspirations (desired attributes) and reality (current actual situation), is used as a central theoretical orientation in this study. Both a change in attributes of the house and/or neighbourhood closer to one's aspiration or lower aspiration levels will lead to a smaller gap. The smaller the gap, the higher the satisfaction. When the gap between aspiration and reality exceeds a certain limit, inhabitants may feel unsatisfied and intend to move house.

Based on prior studies, an integrated model, representing the various direct and indirect relationships will be estimated (Fig. 1). Considering the Chinese literature analysing the relationship between residential satisfaction and mobility is modest, the influence of residential satisfaction and social-demographics on the intention to move will be analysed for residents living in renovated Chinese historical blocks. As residential satisfaction is assumed to be a function of the gap between aspiration and reality, this relationship will be tested. How the residential gap is influenced by social-demographic variables will be analysed. Because the main aim of this analysis is to identify the influence on moving intention, estimation of the relationship between

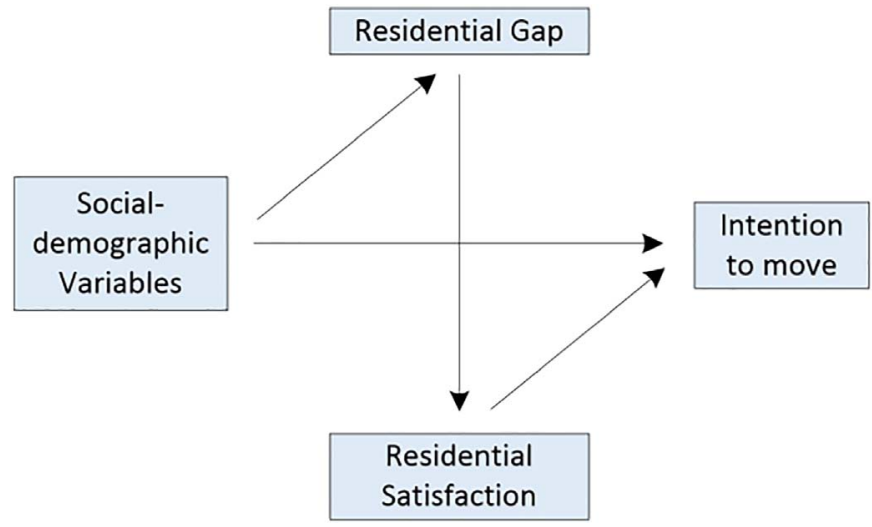

Fig. 1. Conceptual model. social-demographics and residential satisfaction will not be included. Although lifecycle is considered as an significant variable for residential mobility in western literatures, it is found less influential than other variables in Chinese study (Li, 2004). Therefore, life course variables will not be included in this analysis.

Following Clark and Onaka (1983) who identified housing, neighbourhood and accessibility as the three main reasons of voluntary move, a large number of scholars found that housing attributes have more influence on residential satisfaction and mobility compared with the other two groups of variables (e.g., Addo, 2016; Dane et al., 2014; Dieleman \& Mulder, 2002; Fattah, Salleh, Badarulzaman, \& Ali, 2015; Li, 2003; Molin \& Timmermans, 2003; Ren \& Folmer, 2016). Most housing attributes used in previous studies relate to the house itself. To get a more comprehensive understanding of factors which influence residential satisfaction, we include a wider set of factors into our model. More specifically, a set of both housing and environmental attributes are included. Political influence was also included due to the fact that renovation of historical blocks is usually organised by local governments in China.

In terms of social-demographic variables, the commonly used variables in studies of residential mobility include age, gender, tenure, length of stay, supporting elderly, education and type of job. We follow this tradition. However, considering the specific Chinese context, the special household registration system (hukou in Chinese) (Huang et al., 2014) and the stage of renovation are also included.

\section{Data collection}

The data used in this analysis are from a survey conducted in eight historical blocks in two cities of China, Chongqing and Shanghai. Chongqing is located in the Western part of China, while Shanghai is in the Eastern part (Fig. 2). Both cities are the first-tier cities in China. They all have a long history and possess many historical areas. Considering the remaining ratio of historical areas scattering in each city (8 in Chongqing and 14 in Shanghai), three historical blocks from Chongqing and five from Shanghai were chosen for the survey.

The selected blocks are all from different historical areas and they are representative of Chinese historical blocks, namely Ciqikou, Shancheng alley and Zhongshan 4th Road historical block in Chongqing and Julu Road, Shanyin Road, Laochengxiang, Yuyuan Road and Bugaoli historical block in Shanghai. Their size varies from 0.1 to $0.5 \mathrm{~km}^{2}$ in Chongqing and from 0.03 to $0.15 \mathrm{~km}^{2}$ in Shanghai and their population size ranges from 2000 to 14,000 inhabitants. As all blocks

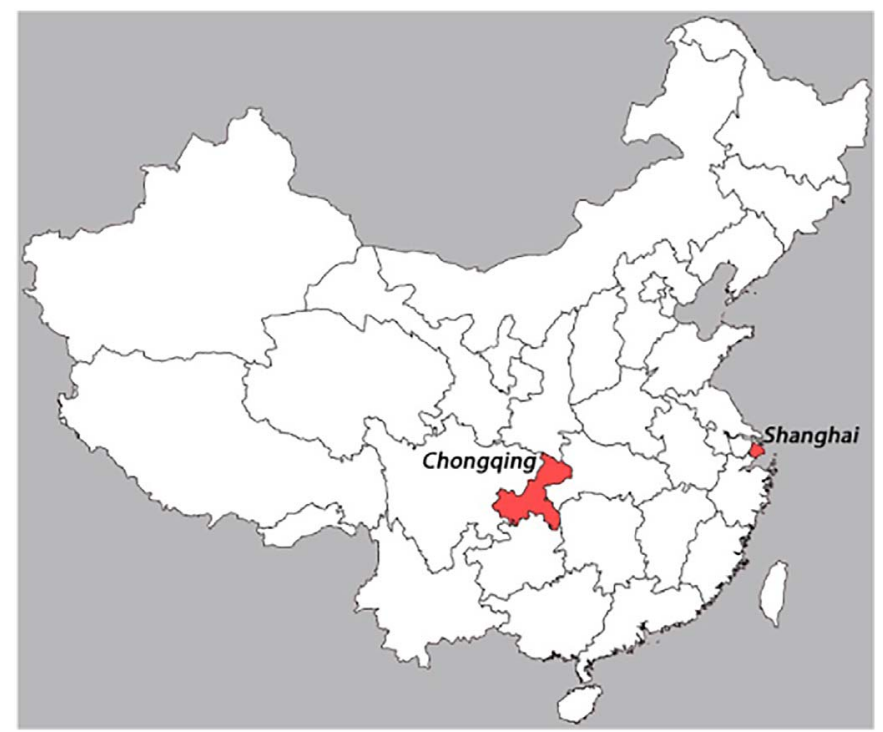

Fig. 2. Location of Chongqing and Shanghai in China. 
are scattered in the centre of city, they have very good transportation connections.

Considering that these blocks have experienced different degrees of renovation, they can be grouped into three renovation stages: Shancheng alley and Laochengxiang are still at the early stage of renovation as few rounds of small renovations took place before and very few local residents moved out. Ciqikou, Julu Road, Shanyin Road and Yuyuan Road blocks are at the middle renovation stage, with at least one round of major renovation. Although they currently do not face any renewal, potentially they may have more renovations in the future. Another 2 blocks, Zhongshan 4th Road and Bugaoli, are already at the late renovation stage: they went through several rounds of renovation and, therefore, new large scale renovation is not expected soon. A large share of their inhabitants has been replaced.

The full survey contains dimensions structured based on classical studies (e.g., Clark \& Onaka, 1983). We differentiate between two main dimensions, housing and environment, each containing five variables. The housing dimension is composed with size of house, proximity to the main road, non-shared kitchen and bathroom, technical quality (defined as the sturdiness of wall and roof without crack and sufficient ventilation) and repair support from government, while the environment dimension consists of distance to the closest mall, road condition, having gas pipe or not, having small community park or not and walkability. Walkability is defined as the extent that the environment is convenient and friendly for pedestrians.

For each attribute, respondents were asked to indicate their current situation, their satisfaction with the current situation and their aspiration level. For instance, for the attribute of technical quality, respondents indicated the current technical quality of their house, their satisfaction about the current quality and the aspired housing quality. The wording of aspiration was such that respondents were invited to indicate their ideal, not the minimum level of acceptance. Based on the judgement of all attributes associated with a particular dimension, respondent' overall satisfaction with that dimension was measured. All satisfaction ratings were measured on a seven-point scale, ranging from "extremely unsatisfied" to "extremely satisfied". As reflected in the different statistical models used, there is a difference of opinion with respect to the question whether such measurements represent an ordinal or an interval scale of measurement. In the choice of our analysis, we assumed the latter, which is in line with the vast majority of prior studies. Finally, information was collected with respect to respondents' social-demographic profiles, overall residential satisfaction and their intention to move house. After the survey, at least 3 semi-structured interviews were conducted in each historical block, which results in $>30$ interviews in total. The latter information is not directly used in this paper, but served in the interpretation of the results of the path analysis.

The survey was conducted between April and June 2015. A random sampling method was used to select respondents. All surveys were distributed at a random time on a random day of the week. Due to the relatively high age and low education level of respondents, all questionnaires were administered on a face-to-face basis. 400 questionnaires were distributed; ultimately 384 valid questionnaires were completed. Due to missing data in one question, only data from 375 questionnaires were used in this analysis.

The average age of the respondents is 55 and $43.5 \%$ of the respondents has been 60 or over (Fig. Fig. 3), which means residents have a relative high age. As shown in Table $1,49.1 \%$ of the respondents are male. $11.7 \%$ of residents live alone, while $34.1 \%$ live with an extended family. Over half of the families do not need to support elderly (62.9\%). Regarding education level, results show that $79.8 \%$ of the respondents possess only a degree lower than high school. Most respondents have hukou from the current city (89.1\%), while only few come from other cities or villages $(10.9 \%)$. In addition, $64.5 \%$ of the respondents was born in the historical blocks or has lived there for over 20 years, and therefore may have some emotional attachment to their neighbourhood. $56.8 \%$ of the respondents rent houses from privates, government or companies compared with $40.8 \%$ having the property right. Only $2.4 \%$ of the respondents living in the historical blocks share property rights with government. As for renovation stages, over half of the respondents come from blocks in the middle renovation stage $(51.2 \%)$, while the percentage of respondents from blocks at an early or late stage of renovation is more or less similar.

In order to reduce the number of estimated variables, all multiple categories were merged into binary categories. Renovation stage was divided into "early renovation stage" and "later renovation stage". Tenure refers to rent the house or not. Family composition includes "living alone" and "living with other relatives", education level was merged into having at least college degree or not. Hukou contains "hukou of this city" and "hukou of other city or village". In the analysis, age and length of stay are used as continuous rather than categorical variables.

\section{Analysis and results}

Different from mainstream studies, the gap between aspiration and reality, defined as the ratio of aspiration and reality, for each variable is included in the model instead of the direct use of that variable. The aspiration and reality for each variable are measured according to their ideal (aspiration) and current situation (reality), respectively. As a consequence, any deviation from the stated aspiration level or value is supposed to lead to a lower satisfaction. In case of continuous attributes, aspiration is not necessarily monotonically increasing or decreasing with increasing attribute values because respondents may have some optimal point in mind. For instance, both less or more than the ideal/aspired number of bedrooms may create burden for residents and thus lead to a lower than the maximum satisfaction.

Let $i$ be an index for individuals and $k=1,2, \ldots, K$ be an index for an attribute. We then define the gap related to continuous attribute $k$ for individual $i$ as:

$G_{i k}=\max \left(0,1-\left|R_{i k}-A_{i k}\right| / A_{i k}\right)$

where $G_{i k}$ represents the gap index of individual $i$ for attribute $k . R_{i k}$ indicates reality (the actual value of attribute $k$ that individual $i$ experiences), while $A_{i k}$ is the aspired value of attribute $k$ for individual $i$. Note that as the gap between aspiration and reality becomes smaller, proportional to aspiration level, $\left|R_{i k}-A_{i k}\right| / A_{i k}$ is approaching 0 and therefore the gap index approaches 1 . Thus, as the mismatch decreases, the gap index increases. In contrast, as the discrepancy between aspired and real situation grows, the gap index decreases. When aspiration is much higher than reality, the gap index approaches 0 . At first glance, this may seem counterintuitive. The reason for this transformation is that we intend to keep the direction of the gap index of continuous variable consistent with the categorical variables. For categorical variables, the match between aspiration and reality is measured. Thus, by applying this transformation, all indices will go in the same direction: a larger gap index refers to a smaller gap, leading to higher satisfaction as the conceptual framework assumes.

When aspiration is much higher than reality, the gap index approaches zero and the gap reaches its maximum. There are few situations that reality exceeds two times the aspiration, for instance, few residents intend to have a much smaller house after divorce. In that case, the gap index was truncated at zero, as indicated by the equation. Alternatively, we could have used a non-linear expression, but because this may cause potential problems later on in the analysis, this alternative was not adopted.

Using the ratio, as opposed to the difference, means that we assume people are more sensitive to the absolute differences between reality and aspirations when their aspirations are relatively low, and less sensitive when aspirations are high.

As indicated, for categorical variables, the gap is coded based on whether there is a discrepancy between residents' aspiration and reality 


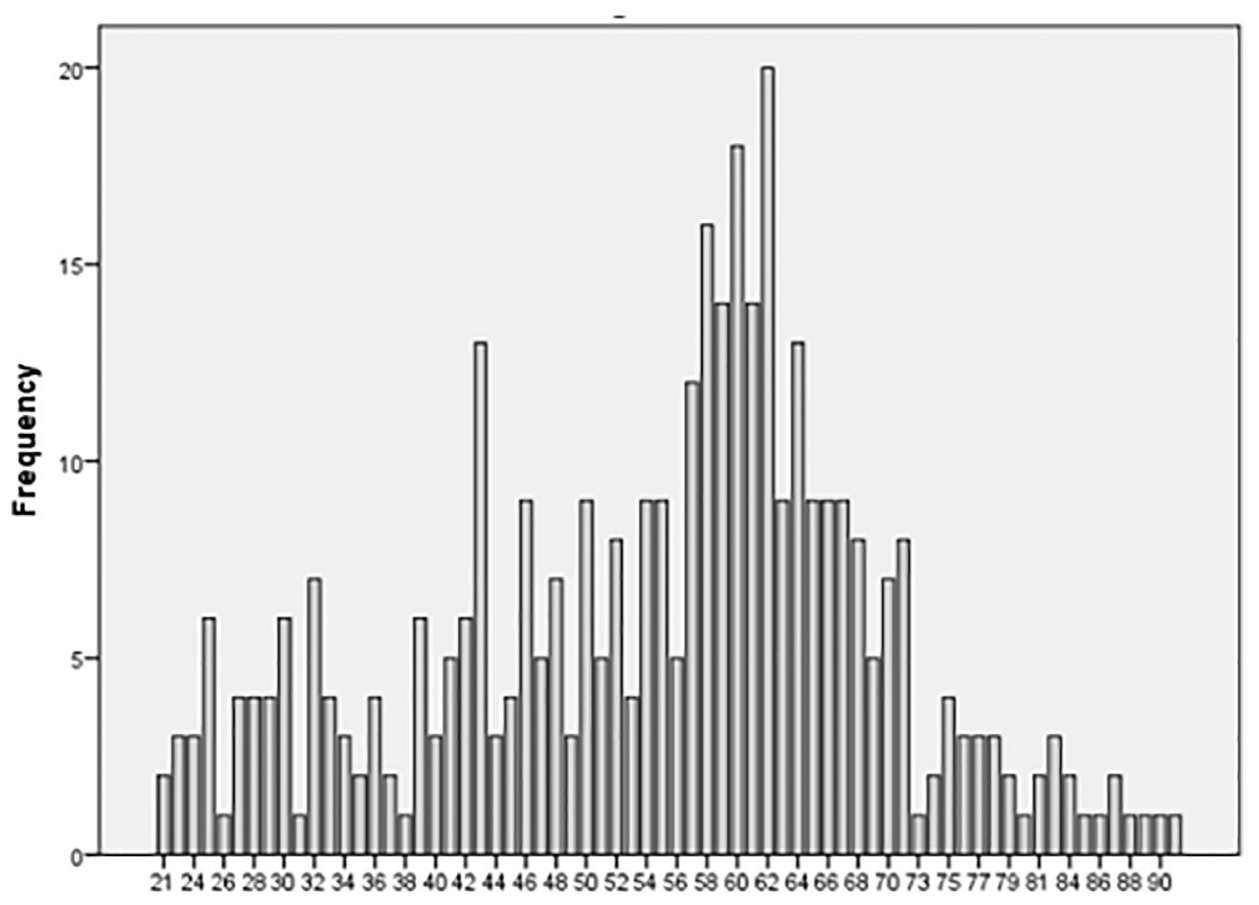

Fig. 3. Age frequency.

Table 1

Description of social-demographic data.

\begin{tabular}{|c|c|c|}
\hline Variable & Category & $\begin{array}{l}\text { Frequency }(\%) \\
\mathrm{N}=375\end{array}$ \\
\hline \multirow[t]{3}{*}{ Renovation stage } & Early stage of renovation & 25.6 \\
\hline & Middle stage of renovation & 51.2 \\
\hline & Late stage of renovation & 23.2 \\
\hline \multirow[t]{3}{*}{ Tenure } & Rent & 56.8 \\
\hline & Bought & 40.8 \\
\hline & Shared right with government & 2.4 \\
\hline \multirow[t]{2}{*}{ Gender } & Male & 49.1 \\
\hline & Female & 50.9 \\
\hline \multirow[t]{4}{*}{ Family composition } & Live alone & 11.7 \\
\hline & With partner & 30.4 \\
\hline & With children/with parents/with others & 23.7 \\
\hline & $\begin{array}{l}\text { With partner }+ \text { children }+ \text { parents/with } \\
\text { partner }+ \text { children }\end{array}$ & 34.1 \\
\hline \multirow[t]{2}{*}{ Supporting elderly } & Yes & 37.1 \\
\hline & No & 62.9 \\
\hline \multirow[t]{3}{*}{ Education level } & Junior high school and under & 45.1 \\
\hline & Senior high school & 34.7 \\
\hline & Junior college and over & 20.3 \\
\hline \multirow[t]{3}{*}{ Hukou } & This city & 89.1 \\
\hline & Other city & 6.4 \\
\hline & Village & 4.5 \\
\hline \multirow[t]{4}{*}{ Length of stay } & 20 years and under & 35.5 \\
\hline & $21-40$ years & 34.6 \\
\hline & 41-60 years & 19.5 \\
\hline & Over 60 years & 10.4 \\
\hline
\end{tabular}

or not. A value of 1 for the gap index indicates that reality matches aspiration and hence there is no gap between them.

We assume that the scales used to measure satisfaction have interval properties. Some scholars may argue the scale is ordinal. It certainly has ordinal properties, but it goes beyond a simple ordinal scale. This is the reason why we assume we are dealing with an interval scale, being in line with the majority of studies using such scales (Speare, 1974; Morris, Crull, Winter, \& Crull, 1976; Molin \& Timmermans, 2003; Liao, 2004; Diaz-Serrano \& Stoyanova, 2010). It allows us to apply a wider spectrum of statistical models. In particular, to understand the complex relationships between intention to move, residential satisfaction, residential gap and social demographics, a path model was estimated to analyse the data. Path analysis can be used to measure both the direct and indirect causal relationships between several groups of variables. Regression is the inherent measurement of this model that tests the existence of causal relationships. A series of regressions is considered simultaneously during estimation. Different from structural equation modelling having latent variables, all variables in path analysis are observable. In this sense, a path model is a special case of a structural equation model that has only a structural model, but no measurement model (Williams, 2015).

\section{Results}

Table 2 and Fig. 4 show the results of the estimated path model. The $\mathrm{x}^{2} / \mathrm{df}$ equals to 1.88 , which is smaller than 3 , the commonly used threshold. CFI $=0.920$, TLI $=0.890$ and RMSEA $<0.05$, which means the goodness-of-fit of the final model is good. Note that all the parameters reported in Table 2 are the standardised coefficients. The first box of the first row of the table indicates the influence of the two selected dimensions of residential satisfaction and social-demographics on the intention to move. Coefficients in the following two boxes in the first row refer to the contribution of the various gap indices between aspiration and reality to housing and environmental satisfaction respectively. All other boxes explain the effects of social-demographics on residential gap.

The results of the estimated path model confirm our conceptual model. The gap between aspiration and reality influences residential satisfaction and further influences the intention to move house. The social-demographic variables have varying impacts on residential gap and mobility.

The moving intention in historical blocks is significantly influenced by both housing and environment satisfaction. Their negative impacts indicate that lower satisfaction will lead to a higher moving propensity. The effect of housing satisfaction $(-0.439)$ influences the intention to move more than the satisfaction about the environment $(-0.138)$, which is also confirmed in the interviews. Three physical and socialdemographic variables (rent, age and early renovation stage) significantly influence the intention to move. The negative sign of rent indicates that residents who rent a house have a lower intention to move compared with those possessing part or full property rights. Older residents and residents living in blocks at later stages of renovation are 
Table 2

Results of causal relationships.

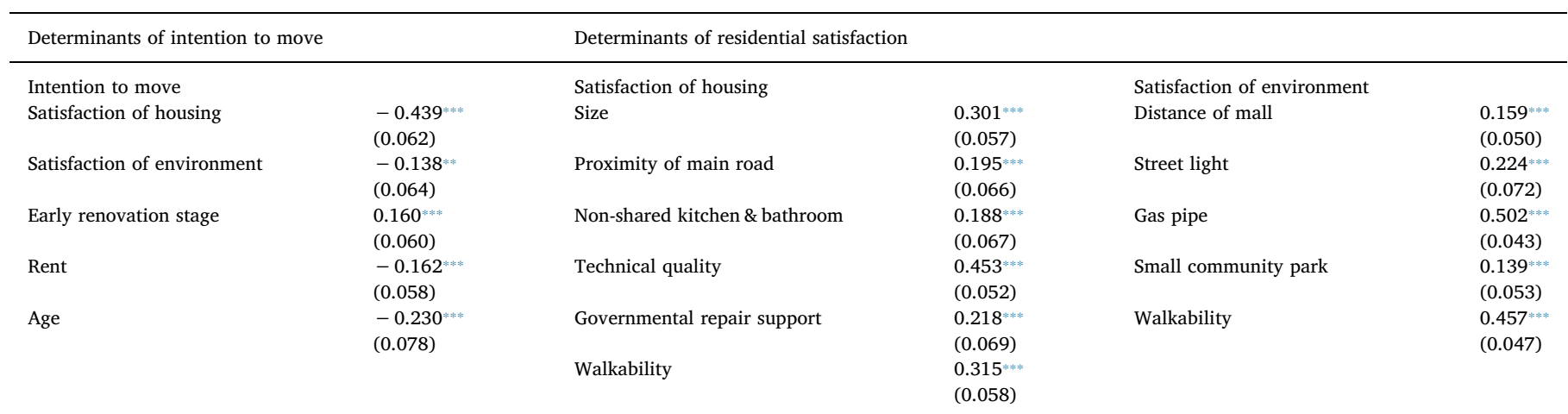

\begin{tabular}{|c|c|c|c|c|c|}
\hline \multicolumn{6}{|c|}{ Determinants of residential gap } \\
\hline Size & & Proximity of main road & & Non-shared kitchen \& bathroom & \\
\hline Early renovation stage & $\begin{array}{l}-0.300^{* * * *} \\
(0.046)\end{array}$ & Early renovation stage & $\begin{array}{l}-0.337^{\text {**** }} \\
(0.056)\end{array}$ & Early renovation stage & $\begin{array}{l}-0.318^{\text {:**** }} \\
(0.054)\end{array}$ \\
\hline Rent & $\begin{array}{l}-0.225^{\text {*N** }} \\
(0.049)\end{array}$ & Length of stay & $\begin{array}{l}0.150 \\
(0.078)\end{array}$ & Rent & $\begin{array}{l}-0.484^{\text {***** }} \\
(0.051)\end{array}$ \\
\hline Male & $\begin{array}{l}-0.135^{* *} \\
(0.055)\end{array}$ & & & Length of stay & $\begin{array}{l}-0.189^{* * * *} \\
(0.069)\end{array}$ \\
\hline Age & $\begin{array}{l}0.199^{* * * *} \\
(0.076)\end{array}$ & & & & \\
\hline Hukou of this city & $\begin{array}{l}-0.149^{\text {**** }} \\
(0.054)\end{array}$ & & & & \\
\hline Technical quality & & Governmental repair support & & Street light & \\
\hline Rent & $\begin{array}{l}-0.206^{* * * *} \\
(0.065)\end{array}$ & Early renovation stage & $\begin{array}{l}-0.128^{* *} \\
(0.060)\end{array}$ & Male & $\begin{array}{l}-0.280^{*} \\
(0.159)\end{array}$ \\
\hline & & Rent & $\begin{array}{l}0.263^{* * * *} \\
(0.060)\end{array}$ & & \\
\hline & & Age & $\begin{array}{l}0.279^{* * * *} \\
(0.089)\end{array}$ & & \\
\hline & & Supporting elderly & $\begin{array}{l}-0.175^{* * *} \\
(0.069)\end{array}$ & & \\
\hline & & Having job & $\begin{array}{l}0.167^{* * *} \\
(0.085)\end{array}$ & & \\
\hline Gas pipe & & Small community park & & Walkability & \\
\hline Early renovation stage & $\begin{array}{l}-0.662^{\text {**** }} \\
(0.039)\end{array}$ & Early renovation stage & $\begin{array}{l}-0.223^{* * *} \\
(0.061)\end{array}$ & Male & $\begin{array}{l}-0.186^{* *} \\
(0.067)\end{array}$ \\
\hline Rent & $\begin{array}{l}-0.241^{\text {**** }} \\
(0.066)\end{array}$ & Rent & $\begin{array}{l}0.243^{\text {****}} \\
(0.063)\end{array}$ & Supporting elderly & $\begin{array}{l}-0.151^{* *} \\
(0.072)\end{array}$ \\
\hline Age & $\begin{array}{l}0.248^{\text {**** }} \\
(0.092)\end{array}$ & & & College degree & $\begin{array}{l}-0.145^{\text {** }} \\
(0.072)\end{array}$ \\
\hline Length of stay & $\begin{array}{l}-0.171^{* * *} \\
(0.087)\end{array}$ & & & & \\
\hline
\end{tabular}

The numbers in the parentheses are standard errors.

$$
\begin{aligned}
& { }^{* * *} \mathrm{P}<0.01 . \\
& { }^{* *} \mathrm{P}<0.05 . \\
& { }^{*} \mathrm{P}<0.1 .
\end{aligned}
$$

also less likely to move.

Regarding the influence of gap on residential satisfaction, as hypothesised, the positive and significant signs of all residential gap variables confirm that, when the gap between aspiration and reality decreases, proportional to aspiration level, residential satisfaction increases. For housing satisfaction, the results indicate that the gap index for technical quality is the most influential variable (0.453), followed by walkability (0.315) and house size (0.301). Considering houses in historical blocks are relatively small compared to those in other urban areas and some respondents are even living in a house as big as 10 square metres with children, the importance of house size is understandable. The gaps related to non-shared kitchen and bathroom $(0.188)$ and repair support from government $(0.218)$ are also statistically significant.

As for the effect of the gap indices on environmental satisfaction, the gap index for infrastructure such as gas pipe (0.502) and walkability in the community (0.371) influences environmental satisfaction more compared with the gap indices for other environmental variables. Higher gap indices for distance to the shopping mall, having a small community park and streetlights are important attributes influencing environmental satisfaction.

The following boxes demonstrate that different social-demographical profiles have significant and varying effects on residential gaps. Here, only the significant social-demographic effects are reported in Table 2 . Renting $(-0.225)$ and early renovation stage $(-0.300)$ negatively affect the gap index of house size, which means residents who rent a house or live in blocks at early renovation stages have a smaller gap index (i.e. proportional to their aspiration level, they tend to experience a bigger gap between aspiration and reality) about house size. Similarly, males $(-0.139)$ and younger people $(0.199)$ seem to also have a smaller gap index for house size compared to females and the elderly. A smaller gap index for house size is also found for residents 


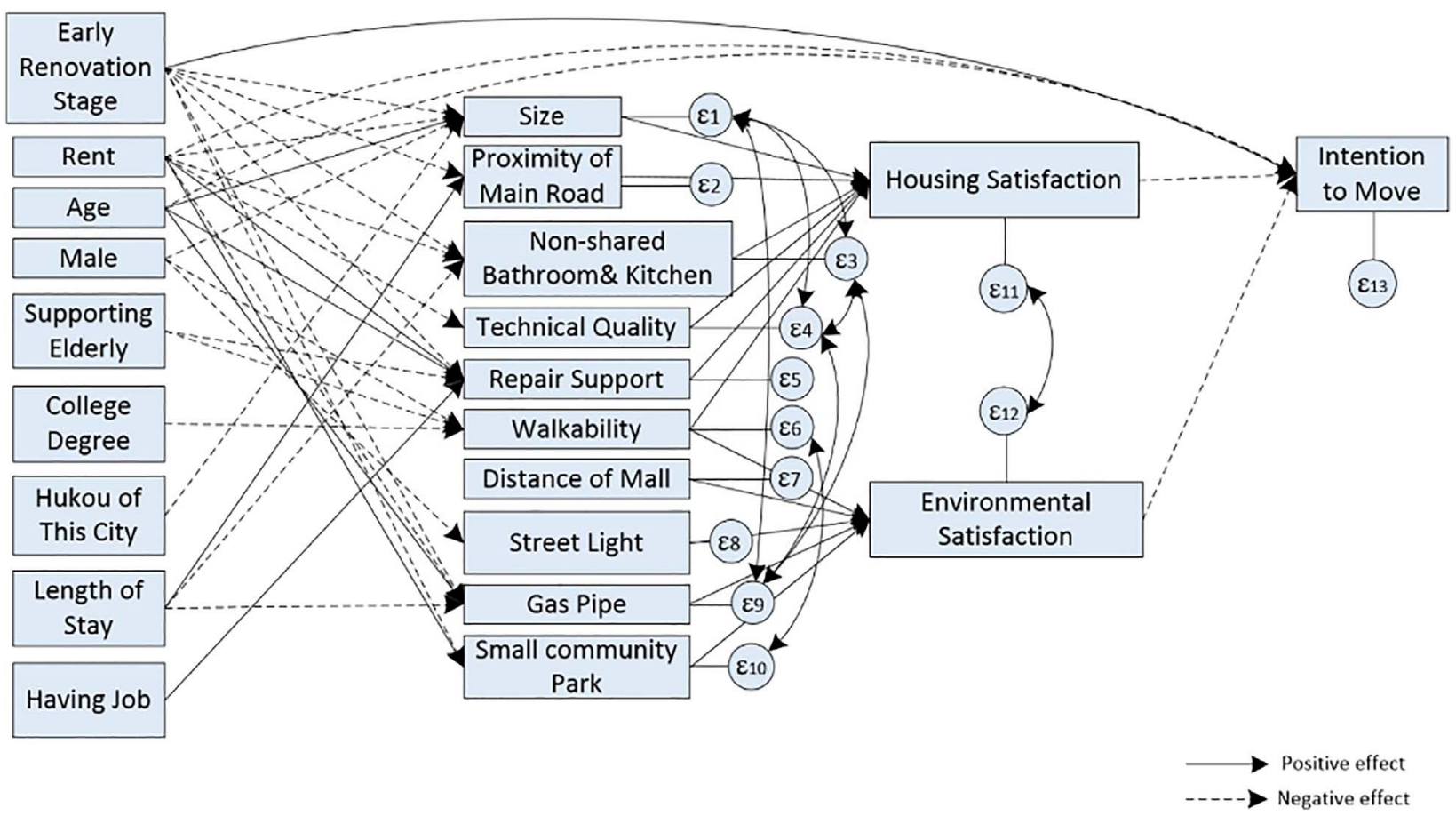

Fig. 4. Results of path analysis.

who own city hukou in those blocks, which indicates that residents with city hukou have a bigger gap between their aspiration and current situation about size of the house.

The gap index of proximity to the main road is significantly influenced by early renovation stage $(-0.337)$, which means residents living in blocks that are at an early stage of renovation are more likely to have a smaller gap index compared to those living in blocks that have gone through more rounds of renovation. Living in those blocks for a shorter time also indicate a smaller gap index about the proximity to the main road (0.150), which implies that people may have to adjust their aspirations if they live in the same block. Different from the gap index of proximity to the main road, longer time of residence leads to a smaller ratio regarding non-shared kitchen and bathroom. This might be because residents' aspirations increase as more households have a non-shared kitchen and bathroom, but their living situation remains same. Residents who rent houses $(-0.484)$ or live in blocks that are at an early stage of renovation $(-0.318)$ are more likely to have a smaller gap index for kitchen and bathroom. As for technical quality, only tenure turns out to be significant, indicating that respondents who rent houses have a bigger gap index compared to house owners.

In terms of repair support from government, different from the effects on other residential gaps, renters have a higher gap index (0.263), which might be because they do not have the property rights, and hence renovation is not of much interest to them. Older residents show a bigger gap index of their aspirations and reality, while families with elderly have a smaller gap index for repair support, which may be due to their higher financial load. Residents with jobs have a higher gap index for renovation support from government, which might be because they have less financial burden.

As expected, the gap index for gas pipes is larger for older residents than for younger people (0.248). For inhabitants living in blocks at the early renovation stage, a bigger gap index for gas pipe is found. Similar to older residents, those who own a house or live in the area for a short time are more likely to have a larger gap index for gas pipes as the negative sign indicates $(-0.241)$.

For small community park, residents from blocks at the early renovation stage or house owners have a smaller gap index compared with those living in blocks at a later renovation stage or renters. Males
$(-0.186)$ and residents with a college degree $(-0.145)$ have a smaller gap index for walkability compared with females and people with a lower education degree. As expected, families with elderly show a smaller gap index for walkability, which means families with elderly experience a bigger gap between their aspiration and reality for the convenient and friendly pedestrian environment (walkability) within their community $(-0.151)$. The residual covariance between variables of residential gap is found to be significant as shown in Table 3. The residual covariances are not fixed at zero the default in the path model to identify the residual correlations between variables. As there is no logical causal relationship between these variables, the residual covariance found may be attributable to the potential hidden variables, like personal preferences and housing characteristics.

\section{Conclusions and discussion}

The social problems caused by residential moves in Chinese historical blocks are becoming increasingly complicated and require more research. Prior studies have mainly focused on the macro level without taking individual residents into consideration. Although the

Table 3

Results of residual relationships.

\begin{tabular}{llll}
\hline $\begin{array}{l}\text { Non-shared } \\
\text { kitchen \& bathroom }\end{array}$ & \multicolumn{3}{c}{ Satisfaction of environment } \\
Size & $\begin{array}{l}0.452^{* * * *} \\
(0.056)\end{array}$ & Satisfaction of housing & $\begin{array}{l}0.385^{* * *} \\
(0.124)\end{array}$ \\
Technical quality & Gas pipe & \\
Size & $0.368^{* * * *}$ & Size & $0.440^{* * * *}$ \\
& $(0.057)$ & & $(0.064)$ \\
Non-shared & $0.428^{* * *}$ & Non-shared & $0.499^{* * * *}$ \\
$\quad$ kitchen \& bathroom & $(0.076)$ & kitchen \& bathroom & $(0.086)$ \\
Gas pipe & $0.370^{* * *}$ & & \\
Walkability & $(0.088)$ & & \\
Small community park & $0.214^{* * *}$ & & \\
& $(0.084)$ & & \\
& & & \\
\hline
\end{tabular}

The numbers in the parentheses are standard errors.

*** $\mathrm{P}<0.01$

${ }^{* *} \mathrm{P}<0.05$. 
determinants of residential mobility have been intensively studied in a large number of studies, this line of research has mainly focused on the direct assessment of influencing variables, with few analysing the mediation effect of residential satisfaction. A comprehensive investigation is still lacking, especially in Chinese historical blocks.

Thus, this paper represents an attempt to systematically analyse the direct and indirect relationships between moving propensity, residential satisfaction, residential gap and social-demographics using a gap-theoretical framework. The integrated causal relations between these variables are confirmed and residual correlations between the variables of residential gap are identified. The results support our assumption that residential satisfaction will not only be influenced by the value of attributes, but also the gap between residents' aspiration levels and the current situation.

The results of the path analysis indicate that the intention to move house is directly driven by residential satisfaction and further indirectly driven by residential gap. Housing and environmental satisfaction both strongly influence moving intention. Among them, housing satisfaction is the most influential variable, which is in line with the findings for other urban areas where housing variables are most significant (Grigolon et al., 2014; Ren \& Folmer, 2016; Ghasrodashti, Majedi, \& Paydar, 2017). Besides residential satisfaction, social-demographics were found to directly influence the intention to move, which is different from Speare's (1974) conclusion that social-demographics only affect residential preference by mediation of residential satisfaction. Older residents were found less likely to move compared with the young, which is consistent with previous studies (Kim et al., 2015; Wu, 2006; Clark \& Huang, 2003). This means that age has a similar impact on residential mobility in both historical blocks and other urban areas. In contrast, residents who own a house or live in blocks of early renovation stage are more inclined to move. It might be because of the potential high profit that house owners can get from selling or renting their houses that are usually located in the centre of city.

As expected, residential satisfaction is positively influenced by the gap index between aspiration and reality, which means an increase of the gap index (i.e. a decrease of gap, proportional to aspiration level) will lead to higher satisfaction. For housing satisfaction, gap indices of technical quality and house size are most important among the housing attributes while the location of house is of less importance. Although house quality and size have also been found significant in studies about other urban areas (Li \& Wu, 2013; Huang et al., 2014; Huang et al., 2015), they are found to be especially important in renovated historical blocks, which is reasonable as interviewers indicated that houses in those historical blocks are always in a worse condition and have much smaller size compared with the ones in other urban areas. Regarding the environmental dimension, the gap indices for walking convenience and infrastructure are of most concern to residents, while the gap index for community parks is of least concern, which is rarely found in previous findings of other urban areas. As those historical blocks are located in the centre of city and not far away from city parks, therefore it might be the reason that they are not interested in community parks. However, infrastructures in those communities are not fully equipped and worse than other urban areas, so they might attract more attentions from residents. Meanwhile, the gap indices for house size, non-shared kitchen and bathroom, technical quality, gas pipe, walkability and community parks are found to have residual covariance between pairs of variables that might be induced by some common hidden factors in the measurement of satisfaction and moving intention.

Regarding the influence of social-demographics on the gap between aspiration and reality, residents living in blocks at the early renovation stage have a smaller gap index (i.e. a bigger gap of aspiration and reality, proportional to aspiration level) about most aspects of housing and environment compared with those living in blocks of later stages. Renters value more improvements in house size, quality, non-shared kitchen, bathroom and gas pipe, but care less about governmental repair and small community parks, which might be because renters are easier to move and do not need to shoulder the responsibility of deterioration of house. Therefore, they are less concerned about the renovation and leisure space compared with house owners. Given the aspiration level, older inhabitants have lower gap for residential elements, such as house size and gas pipe, than the younger inhabitants. They also tend to express lower gap for governmental repair support, which means they concern less about repair support. Males are more interested in the improvement of house size, streetlights and surrounding walkability or have to reduce their aspirations compared with females. Longer residence decreases the gap index for gas pipe and nonshared kitchen and bathroom, but increases the gap index for proximity to the main road. Residents with hukou of the current city also express a smaller gap index about house size. Given the aspiration level, families supporting elderly have greater interest in more renovation support and better walkability, which is similar for families living in the other urban areas (Patterson \& Chapman, 2004). Other social-demographics such as education degree are found to have less impact on the residential gap.

Although residents living in renovated historical blocks face more constraints and complicated situations compared with those living in other urban areas, results from the path model suggest that these two groups of residents have similar interests. For instance, both consider housing satisfaction as the most significant factor influencing the intention to move, and the moving intention decreases as the age of resident increases in both groups. However, some particularity regarding moving propensity of residents in renovated historical blocks still exists. For instance, governmental repair support is found to be significant in these blocks as house quality is worse and residents have a lower income compared with other urban areas. The improvement of infrastructure is more significant for residents in historical blocks as they have worse infrastructure than residents of other urban areas. Although house quality and size have also been found significant in other urban areas, they are considered particularly important in historical blocks because relatively the house quality is worse and house size is much smaller.

These results have important ramifications for urban planning and renovation of historical blocks. First, urban planners should realise that aspirations of people matter. Commonly adopted views that more is better are not necessarily true. Better understanding local needs and aspirations may in fact save a lot of money because it gives planners information about the differences in gaps between residents' aspirations and current or planned reality. Second, the results of our analyses have provided empirical evidence about the relative importance of the various attributes. In case of limited budgets, results indicate that urban planners can enhance satisfaction most by investing in housing attributes, infrastructure and walkability due to the particularity of these renovated historical blocks. Other attributes seem less contributing to residential satisfaction. Third, more governmental repair support should be provided to reduce the deterioration of those historical buildings and better the living environment as having rental property rights restricts residents' action of upgrading their houses. From the results of the survey and the interviews, residents mentioned that governmental repair support is always helpful despite low influence on residential satisfaction due to the insufficiency. Especially for families having elderly to support or residents without job, if aspiration remains, more governmental repair support is important due to their financial loads.

Although this study provides some insights into the complicated relationships between residential gap, satisfaction and intention to move, there is still room for possible improvement and extension. Our measure of gap assumes that the effects of deviations from the aspiration level on satisfaction are symmetric. However, one may hypothesise that (perceptually and cognitively) the gap is larger if reality is lower than aspiration compared to reality exceeding aspiration. Because any measure that has this property likely involves non-linear forms and hence increases the complexity of analyses, and may require methodological advances, in this study we only consider the current 
formulation. We do, however, plan to further explore this limitation in future research.

The current study has used intention to move house as the final dependent variable. As discussed, intentions do not always materialize into real moves. Hence, future research may wish to add the direct and indirect relationships of the selected variables to the question whether the intention to move was followed by a real move or not.

\section{References}

Addo, I. A. (2016). Assessing residential satisfaction among low income households in multi-habited dwellings in selected low income communities in Accra. Urban Studies, 53(4), 631-650. http://dx.doi.org/10.1177/0042098015571055.

Brown, L. A., \& Moore, E. G. (1970). The intra-urban migration process: A perspective. Geografiska Annaler. Series B, Human Geography, 52(1), 1-13. http://dx.doi.org/10. $2307 / 490436$.

Brummell, A. C. (1979). A model of intraurban mobility. Economic Geography, 55(4), 338-352. http://dx.doi.org/10.1126/science.11.277.620.

Brummell, A. C. (1981). Method of measuring residential stress. Geographical Analysis, 13(3), 248-261.

Campbell, A., Converse, P. E., \& Rodgers, W. L. (1976). Satisfaction, aspirations, and expectations. The quality of American life (pp. 583-). Russell Sage Foundation.

Chen, Z., Xu, J., \& Jing, H. (2009). Multi-scale spatial analysis of historic district based on syntax: Taking three lanes and seven alleys in Fuzhou as an example. City Planning Review, 33(8), 92-96.

Clark, W. A. V., \& Coulter, R. (2015). Who wants to move? The role of neighbourhood change. Environment and Planning A, 47(12), 2683-2709. http://dx.doi.org/10.1177/ $0308518 X 15615367$.

Clark, W. A. V., \& Huang, Y. (2003). The life course and residential mobility in British housing markets. Environment and Planning A, 35(2), 323-339. http://dx.doi.org/10. 1068/a3542.

Clark, W. A. V., \& Onaka, J. (1983). Life cycle and housing adjustment as explanations of residential mobility. Urban Studies, 20(1), 47-57. http://dx.doi.org/10.1080/ 713703176.

Dane, G. Z., Griglon, A. B., Rasouli, S., \& Timmermans, H. (2014). Determinants of residential mobility intentions: A mixed binary Logit model. The 19th international conference of Hong Kong Society for transportation studies. 12. The 19th international conference of Hong Kong Society for transportation studies (pp. 1-8). . (Hong Kong, China) http://dx.doi.org/10.1017/CBO9781107415324.004.

Deane, G. D. (1990). Mobility and adjustments: Paths to the resolution of residential stress. Demography, 27(1), 65-79. http://dx.doi.org/10.2307/2061553.

Diaz-Serrano, L., \& Stoyanova, A. P. (2010). Mobility and housing satisfaction: An empirical analysis for 12 EU countries. Journal of Economic Geography, 10(5), 661-683. http://dx.doi.org/10.1093/jeg/lbp045.

Dieleman, F. M., \& Mulder, C. H. (2002). The geography of residential choice. Residential environments: Choice, satisfaction, and behavior (pp. 35-54). Westport, Connecticut: Bergin \& Garvey.

Earhart, C. C., \& Weber, M. J. (1996). Attachment-to-home: A contributing factor to models of residential mobility intentions. Family and Consumer Sciences Research Journal. http://dx.doi.org/10.1177/1077727X960244007.

Fang, Y. (2006). Residential satisfaction, moving intention and moving behaviours: A study of redeveloped neighbourhoods in inner-city Beijing. Housing Studies, 21(2), 671-694. http://dx.doi.org/10.1080/02673030600807217.

Fattah, H. A., Salleh, A. G., Badarulzaman, N., \& Ali, K. (2015). Factors affecting residential mobility among households in Penang, Malaysia. Procedia - Social and Behavioral Sciences, 170, 516-526. http://dx.doi.org/10.1016/j.sbspro.2015.01.077.

Feijten, P., \& van Ham, M. (2007). Residential mobility and migration of the divorced and separated. Demographic Research, 17, 623-654. http://dx.doi.org/10.4054/DemRes. 2007.17.21.

Galster, G. (1987). Identifying the correlates of dwelling satisfaction: An empirical critique. Environment and Behavior, 19(5), 539-568. http://dx.doi.org/10.1177/ 0013916587195001.

Ghasrodashti, R. E., Majedi, H., \& Paydar, M. (2017). Assessment of residential satisfaction in Mehr housing scheme: A case study of Sadra New Town, Iran. Housing, Theory and Society, 6096(March), 1-20. http://dx.doi.org/10.1080/14036096.2017. 1298536.

Green, M. (2014). Social networks and residential mobility in later life: The effects of moving on social network supportive capacity amongst older people in the UK. University of Southampton.

Grigolon, A., Dane, G., Rasouli, S., \& Timmermans, H. (2014). Binomial random parameters logistic regression model of housing satisfaction. Procedia Environmental Sciences, 22, 280-287. http://dx.doi.org/10.1016/j.proenv.2014.11.027.

He, L., \& Yang, C. (2011). Housing satisfaction of urban residents and its influential factors. Journal of Public Management, 8(2), 43-51. http://dx.doi.org/10.1017/ СB09781107415324.004.

He, S. (2015). Understanding residential relocation satisfaction and intention in Guangzhou, China. April 2015, 2015.

He, Y., \& Deng, W. (2014). From management to governance-The role of government in historical block conservation. Urban Planning Forum, 6(219), 109-116.

Hu, F. (2013). Homeownership and subjective wellbeing in urban China: Does owning a house make you happier? Social Indicators Research, 110(3), 951-971. http://dx.doi. org/10.1007/s11205-011-9967-6.

Huang, X., Dijst, M., van Weesep, J., \& Zou, N. (2014). Residential mobility in China:
Home ownership among rural-urban migrants after reform of the Hukou registration system. Journal of Housing and the Built Environment, 29(4), 615-636. http://dx.doi. org/10.1007/s10901-013-9370-5.

Huang, Y., \& Deng, F. F. (2006). Residential mobility in Chinese cities: A longitudinal analysis. Housing Studies, 21(December), 625-652. http://dx.doi.org/10.1080/ 02673030600807084.

Huang, Z., \& Du, X. (2015). Assessment and determinants of residential satisfaction with public housing in Hangzhou, China. Habitat International, 47, 218-230. http://dx.doi. org/10.1016/j.habitatint.2015.01.025.

Huang, Z., Du, X., \& Yu, X. (2015). Home ownership and residential satisfaction: Evidence from Hangzhou, China. Habitat International, 49, 74-83. http://dx.doi.org/10.1016/j. habitatint.2015.05.008.

Huff, J. O., \& Clark, W. (1978). Cumulative stress and cumulative inertia: A behavioral model of the decision to move. Environment and Planning A, 10(10), 1101-1119.

Hui, E. C. M., \& Yu, K. H. (2009). Residential mobility and aging population in Hong Kong. Habitat International, 33(1), 10-14. http://dx.doi.org/10.1016/j.habitatint. 2008.02.001.

Ioannides, Y. M. (1987). Residential mobility and housing tenure choice. Regional Science and Urban Economics, 17(2), 265-287. http://dx.doi.org/10.1016/0166-0462(87) 90050-0.

Jin, J. (2005). Protection and management of historical blocks. Chinese Public Administration, 11(245), 74-76. http://dx.doi.org/10.1017/СBO9781107415324. 004.

Kährik, A., Leetmaa, K., \& Tammaru, T. (2012). Residential decision-making and satisfaction among new suburbanites in the Tallinn urban region, Estonia. Cities, 29(1), 49-58. http://dx.doi.org/10.1016/j.cities.2011.07.005.

Kearns, A., \& Parkes, A. (2003). Living in and leaving poor neighbourhood conditions in England. Housing Studies, 18(6), 827-851. http://dx.doi.org/10.1080/ 0267303032000135456.

Kim, H., Woosnam, K. M., Marcouiller, D. W., \& Aleshinloye, K. D. (2015). Residential mobility, urban preference, and human settlement: A South Korean case study. Habitat International, 49, 497-507. http://dx.doi.org/10.1016/j.habitatint.2015.07. 003.

Kwon, H. J., \& Beamish, J. O. (2013). Older adults in multifamily housing: Residential satisfaction and intention to move. Family and Consumer Sciences Research Journal, 42(1), 40-54. http://dx.doi.org/10.1111/fcsr.12037.

Landale, N. S., \& Guest, A. M. (1985). Constraints, satisfaction and residential mobility: Speare's model reconsidered. Demography, 22(2), 199-222.

Li, S. (2003). Housing tenure and residential mobility in urban China: A study of commodity housing development in Beijing and Guangzhou. Urban Affairs Review, 38(4), 510-534. http://dx.doi.org/10.1177/1078087402250360.

Li, S. (2004). Life course and residential mobility in Beijing, China. Environment and Planning A, 36(1), 27-43. http://dx.doi.org/10.1068/a35243.

Li, S., \& Song, Y. (2009). Redevelopment, displacement, housing conditions, and residential satisfaction: A study of Shanghai. Environment and Planning A, 41(5), 1090-1108. http://dx.doi.org/10.1068/a4168.

Li, Z., \& Wu, F. (2013). Residential satisfaction in China's informal settlements: A case study of Beijing, Shanghai, and Guangzhou. Urban Geography, 34(7), 923-949. http://dx.doi.org/10.1080/02723638.2013.778694.

Liao, P. (2004). Emotional attachment, residential satisfaction, and mobility propensity. Journal of Population Studies, 28, 49-79.

Mohit, M. A., \& Adel Mahfoud, A.-K. (2015). Appraisal of residential satisfaction in double-storey terrace housing in Kuala Lumpur, Malaysia. Habitat International, 49, 286-293. http://dx.doi.org/10.1016/j.habitatint.2015.06.001.

Molin, E. J. E., \& Timmermans, H. J. P. (2003). Testing hierarchical information integration theory: The causal structure of household residential satisfaction. Environment and Planning A, 35(1), 43-58. http://dx.doi.org/10.1068/a3416.

Morris, E. W., Crull, S. R., Winter, M., \& Crull, S. U. E. R. (1976). Housing norms, housing satisfaction and the propensity to move. Journal of Marriage and Family, 38(2), 309-320.

Oh, J. (2003). Social bonds and the migration intentions of elderly urban residents: The mediating effect social bonds and the migration intentions of elderly urban residents: The mediating effect of residential satisfaction. Population Research and Policy Review, 22(2), 127-146.

Onaka, J. L., \& Clark, W. A. V. (1983). A disaggregate model of residential mobility and housing choice. Geographical Analysis, 15(4), 287-304. http://dx.doi.org/10.1111/j. 1538-4632.1983.tb00788.x.

Parkes, A., Kearns, A., \& Atkinson, R. (2002). What makes people dissatisfied with their neighbourhoods? Urban Studies, 39(13), 2413-2438. http://dx.doi.org/10.1080/ 004209802200002703.

Patterson, P. K., \& Chapman, N. J. (2004). Urban form and older residents' service use, walking, driving, quality of life, and neighborhood satisfaction. American Journal of Health Promotion, 19(1), 45-52. http://dx.doi.org/10.4278/0890-1171-19.1.45.

Phipps, A. G. (1989). Redisential stress and consumption disequilibrium in the Saskatoon housing market. The Regional Science Association, 67(1), 71-87. http://dx.doi.org/10. 1007/BF01934668.

Phipps, A. G., \& Carter, J. E. (1984). An individual-level analysis of the stress-resistance model of household mobility. Geographical Analysis, 16(2), 176-189.

Posthumus, H., Bolt, G., \& van Kempen, R. (2014). Victims or victors? The effects of forced relocations on housing satisfaction in Dutch cities. Journal of Urban Affairs, 36(1), 13-32. http://dx.doi.org/10.1111/juaf.12011.

Rabe, B., \& Taylor, M. (2010). Residential mobility, quality of neighbourhood and life course events. Journal of the Royal Statistical Society. Series A, Statistics in Society, 173(3), 531-555. http://dx.doi.org/10.1111/j.1467-985X.2009.00626.x.

Ren, H., \& Folmer, H. (2016). Determinants of residential satisfaction in urban China: A multi-group structural equation analysis. Urban Studies. http://dx.doi.org/10.1177/ 
0042098015627112.

Ruan, Y. (2004). Protect our root: City development and protection of culture heritages. Urban and Rural Development, 7, 8-11. http://dx.doi.org/10.1017/ CBO9781107415324.004.

Speare, J. A. (1974). Residential satisfaction as an intervening variable in residential mobility. Demography, 11(2), 173-188. http://dx.doi.org/10.2307/2060556.

Tang, Y. (2012). A study of housing aspiration and social interactions of China's generation Y. China: Industrial and Commercial University of Chongqing.

Tao, L., Wong, F. K. W., \& Hui, E. C. M. (2014). Residential satisfaction of migrant workers in China: A case study of Shenzhen. Habitat International, 42, 193-202. http://dx.doi.org/10.1016/j.habitatint.2013.12.006.

Temelová, J., \& Dvořáková, N. (2012). Residential satisfaction of elderly in the city centre: The case of revitalizing neighbourhoods in Prague. Cities, 29(5), 310-317. http://dx.doi.org/10.1016/j.cities.2011.11.015.

Wang, J. (2008). The cities in the notebook. SDX Joint Publishing Company.
Waziri, A. G., Yusof, N., \& Abd Rahim, N. M. S. (2014). Occupants housing satisfaction: Does age really matter? Urban, Planning and Transport Research, 2(12), 341-353. http://dx.doi.org/10.1080/21650020.2014.935467.

Williams, R. (2015). Intro to path analysis.

Wolpert, J. (1965). Behavioral aspects of the decision to migrate. The Regional Science Association, 23, 159-169.

Wu, W. (2006). Migrant intra-urban residential mobility in urban China. Housing Studies, 21(5), 745-765. http://dx.doi.org/10.1080/02673030600807506.

Yang, J., \& Wu, M. (1999). Modern urban renewal. Nanjing: Southeast Univeristy Press.

Zheng, L., \& Yang, C. (2005). Public participation in the dynamic conservation of historic districts. City Planning Review, 7(9), 63-65. http://dx.doi.org/10.1017/ CBO9781107415324.004.

Zhong, X., \& Kou, H. (2015). Influende of community participation on the historic block conservation: A case study on the post-disaster reconstruction of Xijie Historic Block, Dujiangyan. City Planning Review, 39(7), 87-94. 